\title{
Contestations of Self and Other in Researching Religion, Gender and Health among Migrant Women
}

\section{Delipher Manda \\ Federico Settler}

\begin{abstract}
This essay is a critical reflexive account of contestations over power and ethics related to getting ethical approval for a study on sexual and reproductive choices among migrant women in pentecostal congregations in South Africa. We found that despite the feminist method and theory that undergirded the proposed study, the University Ethics Committee regarded the researcher's insider position as an obstacle to scholarly inquiry. Notwithstanding the marginal position of religion and theology in humanities and the social sciences (McCutcheon 2003), we found that a number of issues related to procedural ethics and power emerged as obstacles in the research, seemingly because the project was to be conducted by a migrant woman of colour. We contend that it is not uncommon that women, and black women researchers in particular, are required to demonstrate competency as if they are imposters or space invaders to the academic culture (Ahmed 2012; Mirza 2015). Similarly, where similar proposals using, for example, mixed methods and emic approaches might be welcomed as methodological innovation, our experience has been that insider/ indigenous methodologies are too easily dismissed as incompetence, or as being provisional and lacking substance (Smith 2006; Burgess-Proctor 2015). We propose to review a particular case study to show how ethical approval and governance processes intended as scientific gatekeeping, can serve to undermine the emergence of local and gendered ways of knowing and being. Thus in this article we argue that ethic committees' biases result in (a) privileging positivist knowledge schemas over indigenous and feminist approaches; and (b) entrench particular gendered and racialised
\end{abstract}


ideas about the emic researcher; and (c) in this case, re-inscribe narrow paternalistic ideas about migrant social worlds, agency, and self-fashioning. It is our intention to map the pedagogical trajectories and tensions that were sparked by the ethical issues faced by us as scholars of colour, and finally we will show how we sought to navigate these obstacles, as researcher and supervisor.

Keywords: Research Ethics, Power, Gender, Race, Migration.

\section{Introduction}

This article focuses on contestations over ethics and power in a research project that explored the role of faith and migration in relation to African Christian women's sexual and reproductive health rights. The contestation emerged out of the differing epistemological and ethical positions of the university's ethics committee and that of the researcher and her supervisor. In this project I Delipher - was the researcher and Federico was my supervisor. In the research project we discuss here I focused on an African Pentecostal church in a provincial city with a high number of migrants, and the research project formed part of a National Research Foundation funded initiative on Religion and Migration in Postcolonial Africa. This initiative set out to do a series of empirical studies on migration and religion in Southern Africa. The overall aims of the project were to examine the different ways that migrants deployed religion and faith in the migratory process, and secondly, to consider and understand how migration changes people's religion institutions, beliefs and practices. The interest in studying migrant women's experiences was motivated by two key factors. Firstly, as a migrant woman, I sought to do research that was concerned with the lived experience of migrant women in SA. Secondly, as a pastor's wife, located in the Christian pentecostal tradition, I was also very aware of the challenges that women face in terms of their bodily rights, and sexual and reproductive rights in particular. Through this study I was able to marry these two interests. The central research question was: How do migrant women's faith influence their sexual reproductive and health choices?

However, in order to proceed with the empirical study that included interviews with six migrant women, I needed to get ethical approval. In order to get ethical approval, I needed to satisfy the University's Research Ethics 
Committee requirement that the privacy, safety, social standing and general welfare of project participants would be protected, and that the risk to participants would be attended to with respect to their physical, psychological, social and economic wellbeing (Levine 1988). My supervisor and I would soon come to agree with Goodyear-Smith, Lobb, Davies, Nachson and Seelau who have argued that 'the determination of potential risk is neither obvious nor intuitive, and is open to interpretation by ethics committees according to their assessment of the context' (2002:5). Likewise, Amanda Burgess-Proctor (2015) has noted that the safeguards that feminist researchers are often expected to comply with to ensure that participants are protected, may actually result in the disempowerment of the participants. She concludes that these two aims need not be mutually exclusive. It is in this regard that we hope to illustrate below how the university's ethics committee's assumptions about migrant women as particularly vulnerable, prejudiced their assessment of risk, both in terms of the participants and the researcher.

According to Asamoah-Gyadu (2010) Pentecostal Christians are among the most transnational among Christian religious migrants, and Anderson (2006) goes further to assert that Pentecostalism fulfils a felt need in the religious market in Africa and the African diaspora. In particular, the theological teaching in these churches are strongly oriented towards social and bodily piety, through abstaining from things like 'smoking, alcohol, gambling, watching commercial films, swearing, to avoid non-marital sexual relationships' (Brodwin 2003:5). Yet, despite the strict moral ethics in the Pentecostal tradition, they provide a strong sense of belonging which has resulted in high representation of migrants in Pentecostal congregations (Nunez 2014). While scholars such as Adogame (2008) have shown that Pentecostal teachings can also offer mobility and autonomy to women in the transnational spaces, these churches by and large harbour tensions between theological and biomedical discourses over bodily autonomy of its members. In the research proposal, I suggested that African Pentecostal churches generally hold very strict moral positions about women's sexualities through privileging fertility and reducing the status of women without children (Yebei 2000). Thus my study sought to explore how migrant women who subscribe to Pentecostalism, mediated their sexual and reproductive health choices.

As we embarked on this research project as student and supervisor, we shared a clear understanding that in studying migrant women's experiences, we would take account of their experiences in ways that were empowering. We 
endeavoured to continually reflect on our respective positions as a migrant woman researcher and a South African man with varying degrees of privilege and power, despite our proximity to the research participants. We discussed at length the literature cited above as well as my position as a migrant woman researcher in a middle class, South African University within a white European scholarly tradition. In this regard we found Heidi Mirza's remarks about black women in the academy useful in resisting the force of inherited tradition. She writes of black women in the academy:

In their space on the margin, with their quiet and subversive acts of care and 'other ways of knowing', these women operate within, between, under and alongside the mainstream educational and labor mar-ket structures, subverting, renaming and reclaiming opportunities ... through the transformative pedagogy of 'raising the race' (Mirza 2015:8).

In this way we agreed that my emic position was an asset to the development and execution of the research project, because I am a sexually active, married black migrant woman, who was also located within the African Pentecostal religious tradition (although in a different congregation). I believed that as a migrant woman I was well placed to enjoy the trust of the participants and to be an empathetic ally. Further, having experienced the challenges of migration myself, I enjoyed the recognition and trust of my peers both insofar as they expected me to understand their faith position, and keep their confidence. It has not been irregular for me to enjoy the confidence of fellow migrant women and help them find relief through solidarity and counselling.

\section{A Complex Intersection: Gender, Migration, Religion and Health}

A number of studies have shown that migrant women consistently encounter barriers to social security and health services (Foley 2005; Scheppers, van Dongen, Dekker, Geertzen \& Dekker 2006), and the reasons that are often cited for limited access are; (a) migrants' lack of health insurance; and (b) their inability to speak the local language which prevents them from communicating adequately with their physician. For example, a South African study in 2005 by Perberdy and Dinat (2005) confirmed that migrants are less inclined to visit public hospitals and outpatient clinics, but that when they do, and despite 
struggles to get access to services, migrant women seek family planning at a higher rate (44\%) than their South African counterparts $(29 \%)$. In addition to the structural barriers that migrant women face in accessing health services, we hypothesised that religion and culture added a further layer of negotiations that migrant women must navigate. This was informed by the fact that while African cultural traditions tend to privilege fertility and encourage childbearing, Pentecostalism assign decisions about family-planning to the husband, coupled with discourses of submission from women.

In my approach to the church leadership, I was careful not to offend my prospective hosts because we knew that Pentecostal churches would be suspicious that I - a university trained religion scholar - might want to 'liberate' women away from their Pentecostal faith. Thus I spent several months reassuring and convincing the church leadership that I was committed to upholding the social standing of the church and that I would not undermine their teaching. We were acutely aware that both Pentecostal churches and African patriarchies privilege women's fertility and reproduction (Yeatman \& Trinitapoli 2008; Agadjanian \& Yabiku 2014). While negotiating access to the church as research site, I tried to remain aware of, and sensitive to Pentecostal churches' largely conservative attitude towards family planning - which is often equated with abortion, and thus the taking of life (Burchardt 2011). Despite these theological anxieties, it took several meetings with the church leadership in late 2015 before I was finally granted permission by the church to conduct the research. The church agreed that interviews could be conducted at the church's service centre, although this was not compulsory.

From among the members of the congregation, I planned to interview six migrant women between 20 and 45 years of age, presumed to be sexually active, and who had been active members of the church. The women I eventually interviewed were from Ghana, Zambia and Zimbabwe, and had been active members of this church for more than one year. Of the six migrant women one was married, one was divorced for two years, while another was going through divorce at the time of the interview. Of the remaining three, two were engaged and one was single. The selection criteria and context of the study reflected the focus of the study - narratives of sexual and reproductive choices among religious migrant women. Similarly, the interview guide was structured to examine three broad areas: the first four questions focussed on the migratory experiences of the women, the next four questions related to the migrant women's access of health care facilities in South Africa, and the final 
three questions addressed the role of religion in mediating sexual and reproductive choices for themselves, or with their partners.

Thus in formulating my research question and negotiating access to the research field, I was careful not to challenges the Pentecostal church's seeming silencing of women's sexual and reproductive rights, nor to advocate feminist critiques of women's positions in their churches. The sensitive relationship to the church (as research site) emerged as one layer of precarity, while my determination to overcome the marginalization of black women's lived experience in academic research was another, and finally the precarity of being a black migrant woman researcher who is made to feel out of place in South Africa and the academy in general. Getting the approval of the church had loomed large over this study, and thus their approval and support of this study was a significant milestone for me. We presumed that the study would enjoy similar approval from the University Ethics Committee, since the research proposal focused on understanding the everyday lived experience of black women with respect to mediating, and accessing services for sexual and reproductive rights and choices. We proceeded to complete the research proposal and rigorously discussed the ethical consideration related to my positionality. We also sought to pay attention to avoiding triggers, such as intimate partner violence, by focusing on participant's agency in personal histories about sexual and reproductive health.

\section{Contestations over Ethics and Patronage in Researching Gender and Migration}

While we recognised that as researchers, we put various measures in place to minimize the negative impact of our research on the women targeted in this study, we also spent time thinking through and interrogating the assumptions of innocence and universality of ethical principles generally applied in research such as autonomy, non- maleficence, justice and beneficence, privacy and justice. The history of ethics in research is concerned with regulating relations of power between the researcher and the participants, all the while informed by ideas about who is doing research, where, and about whom. While unequal relations of power existed between the migrant women participants and myself as a university-based researcher, because I was also an insider, both as a Pentecostal and as a migrant, we realized that traditional assumptions about power and ethics would not apply in the same manner. In fact, we considered 
my proximity in status and life experience to that of the participants a valuable asset for establishing rapport and trust in the research process.

Thus we explored the following considerations, in addition to the ethical requirements of the university. We took as a starting point Pat Caplan's (2003) four main observations about the relationship between power and ethics. She asserts (a) that ethical consideration must permeate all aspects of a discipline; (b) that all ethics are political; (c) that reflexivity is central; and (d) that ethics include rigorous critique of self and your discipline (Caplan 2003). In foregrounding this research project with the framework advocated by Caplan, we engaged in a continuous self-reflection and critique in relation to the ethical position of the researcher to the participants. We assumed that this widely advocated practice would satisfy the University Ethics Committee, but we under-estimated the extent to which my positionality as migrant woman researcher would become a point of contestation.

This was brought home to us after I had completed the research proposal and found my application for ethical clearance delayed due to some reservations by the committee. This in itself was not irregular, but we noted the committee's particular concern that all migrant women may have experienced sexual abuse and/or have been in dependent relationships. This was notable because of the fact that nowhere in the proposal, including its rationale or selection criteria, did I ever suggest or hint that experiences of trauma or violence would form part of the interview focus. From the deliberations with the University Ethics Committee, which we discuss at length below, we came to understand that migrant women (myself included) were not regarded as autonomous and agentic persons by the ethics committee. The idea of migrant women they seemed to articulate to us was one where we were seen as dependent migrants accompanying family - fathers, brothers and husbands (Hondag-neu-Sotelo 2000; Simone 2000), or presumed to be fleeing " bad patriarchies" located in distant places and in racialised bodies' (Keskinen, Tuori, Irni \& Mulinari 2009: 5). These two ideas of the passive, silent suffering migrant women appeared to then be super-imposed on this research project, by the University Ethics Committee - and thus the committee perpetuated the idea of migrant women as perpetual victims, vulnerable, and particularly deserving of patronage and protection. For me this means that my epistemological stance of asserting migrant women's agency was not acceptable to the University Ethics Committee.

Initial ethical concerns were raised three months after my application for ethical clearance was submitted, but the protracted process that followed 
revealed a great deal about the university's orientation towards black women as researchers. Although the MA programme I was part of was one year in duration, the ordeal with the ethics committee took more than six months. This long duration was quite irregular because, out of eight sociology of religion students, my ethics application took the longest. This although, in our view, my proposal was less contentious than several other projects in my cohort. Some of the other research topics included a doctoral research project on coming-out narratives of atheists as social minorities, and a MA project on the sociospiritual development of children in migrant households; both these proposals were approved in less than four weeks. Using the limited sample of eight graduate students registered in this programme between 2014 and 2017, we profiled the ethics application and processing time according to race and gender, and found the following:

\begin{tabular}{|l|l|l|l|l|l|}
\hline Degree & Race & Gender & No. & $\begin{array}{l}\text { Type of } \\
\text { Research }\end{array}$ & $\begin{array}{l}\text { Ethics } \\
\text { Approval } \\
\text { Period }\end{array}$ \\
\hline PhD & African & Male & 2 & Empirical & $\begin{array}{l}\text { Under 3 } \\
\text { months }\end{array}$ \\
\hline MA & Asian & Male & 1 & Empirical & $\begin{array}{l}\text { Under 1 } \\
\text { month }\end{array}$ \\
\hline & Asian & Male & 2 & $\begin{array}{l}\text { Empirical (1) } \\
\text { Non- } \\
\text { Empirical (1) }\end{array}$ & $\begin{array}{l}\text { Under 1 } \\
\text { month } \\
\text { months }\end{array}$ \\
\hline & White & Female & 1 & Empirical & $\begin{array}{l}\text { Under 1 } \\
\text { month }\end{array}$ \\
\hline & African & Female & 2 & $\begin{array}{l}\text { Empirical (1) } \\
\text { Non- } \\
\text { Empirical (1) }\end{array}$ & $\begin{array}{l}\text { Under 3 } \\
\text { months } \\
\text { More than 6 } \\
\text { months }\end{array}$ \\
\hline
\end{tabular}

While we recognise that the sample is small and that there are many differences between the ethics applications, the students all received the same empirical training, had the same supervisor and met on a regular basis as a group, where students shared their respective research experiences. Every student in the 
cohort was required to include a positionality statement with respect to the phenomenon they set out to interrogate. These cohort meetings provided the site from where the second author (as the main supervisor) noticed differences in processing and approval times of research ethics application. What became evident over this period was that there seemed to be arace and gender bias in the processing of applications for ethical clearance. Black African men and women saw their applications take significantly longer than their White and Asian peers. While we had concerns about this anomaly, it was not until we examined the detailed ethics queries directed at me that we began to notice the biases in the University Ethics Committee's reports. This brought to mind Pat Caplan's assertion that 'all ethics are political' as well as other scholars' findings about the inconsistencies and varying judgements dispensed by ethical approval committees (Abbott \& Grady 2011; Caulfield 2011). While there are a number of studies such as by Vadeboncoeur, Townsend, Foster and Sheehan (2016) pointing to variations in applying or interpreting rules of ethical governance in research, we primarily seek to show how both universalizing and intuitive ethical rulings serve to frustrate the visibility and recognition of women and indigenous researchers.

With respect to the review of feminist research proposals, Amanda Burgess-Proctor (2015) argues that most ethics committees rely on conventional, positivist approaches, which means that they are generally unfamiliar with the range of methodologies deployed by feminist researchers. It is our opinion that unlike the libertarian approach in research ethics (Dingwall 2008; Hammersley 2009), our university follows a paternalistic approach to research ethics (Garrard \& Dawson 2005) insofar as its Ethics Committee appears to see themselves as tasked with protecting the interests of the participants, through making decisions about what constitutes acceptable levels of risk. In this case queries from the committee were dispensed in two phases. Three months after submitting the application we received a communication that asked for clarity on the methodology, specifically: how the women would be recruited and where they would be interviewed. It also asked about translation into the vernacular, despite the fact that the proposal clearly indicated that interviews will be conducted conversational English because the participants are likely to be from very different countries. Lastly, the committee required a more detailed account about the referral service for counseling. While the first two issues were relatively easily resolved, issues around the referral service became a major obstacle to getting ethical approval. From the 
initial ethics queries we cite two issues among other that were raised by the committee:

- How will the PI deal with women who need counselling as a result of 'telling their story'?

- Please relook at Question 3.1 (of the protocol) as some of the women may live in vulnerable circumstances and may have / most likely have been traumatized by rape in dependent relationships, etc.

While the remainder of the queries were procedural, the two cited here highlighted psychological risk and as such we responded accordingly. We set aside our objection with the ethics committee assumptions, and I revised the proposal according to their requirements and incorporated a detailed referral sheet referring participants to the local LifeLine Counselling Centre, and offered a rationale. Below we cite from the response letter I sent to the Ethics Committee:

- I have developed a 'Referral Information Sheet' for women who might require counselling. I recommend LifeLine Counselling Centre (near to the Church) because they are based in the city and because they have dedicated service for migrants (refugee counselling service).

- After consultation with my supervisor, we agreed that this research is not focused on women who are likely to have experienced trauma or stressful life circumstance. Distress is not a critical indicator in my sampling criteria nor in the research focus. The research project is based on the understanding that migrants are people who cross borders. This project in part seeks to challenge the idea that all migrants are necessarily victims - and therefore focuses on the everyday, lived experience of migrants. My supervisor and I are in agreement that this research will focus on migrants without any assumption about their circumstances prior to coming to South Africa.

As a phenomenological study, we felt that the rationale sent to the University Ethics Committee offered an account of the feminist ideological and epistemological orientation of the study, and despite the egalitarian orientation of the study, we nevertheless made sure that risk mitigating measures, such as 
anonymity, safety and a dedicated referral services were put in place. We agree that a researcher's indigenous background or the fact that she might hold similar religious beliefs to her participants does not 'authorise carte blanche status in the field' (Jacobs Huyey 2002:793), but we believe that it is possible to be a contentious insider, who stands in solidarity and empathy with her participants. This approach is advocated established feminist scholars such as by Fatima Mernissi (1991) and Ivone Gebara (1999). Both Mernissi and Gebara set privileged justice over participant autonomy as they critiqued religious patriarchies and carved out an epistemological space for critical (insider) feminist narratives drawn from the everyday lives of women within their respective traditions. In wrestling with the implications of the ethical query, we came to understand that the University Ethics Committee assumed a protectionist stance in terms of reducing possible harm to the research participants and as such presented a diminished appreciation of justice for and solidarity with the research participants in their ethical review. Despite drawing on Lanita Jacobs-Huey's work, where she asserts that 'all scholars, particularly native ones, must diligently strive to negotiate legitimacy in the field' (2002:793), we remained anxious about the tensions between the committee's support for a feminist project giving voice to women's lived experience, and their apparent disapproval of a religious insider, migrant women as principal investigator (PI) for this study. Thus the contestation over the referral service not only revealed an ideological tension with the committee over the view of migrant women as victims but it also exposed anxieties about my capabilities as a feminist researcher.

Since my research was primarily located within a Black Feminist framework, it took as a starting point the interlocking nature of oppression (Collins 1991) and thus I took for granted that black female researcher and the black female participant potentially have a closer relation in as far as it relates race, class, gender and ethnicity. Thus our skepticism about the Ethics Committee's view of migrant women was significantly informed by (a) the ideological orientation of the research project - to excavate the agentic aspects of migrant women's everyday lives; and (b) my lived experience as a black migrant woman in South Africa. Collins notes that in negotiating credibility between the researcher and the research participant that relies on 'interlocking nature of oppression' (1991:41) could enhance or frustrate the research efforts and thus a high level of critical self-reflectivity is required. Therefore, JacobsHuey and Collins (2002) caution researchers against simply relying on 
assumed similarities with research participants. In this regard the work of Joy Owen (2005) and Diane Wolfe (1996) discuss the issue of power and ethics in the research relationship, especially in feminist research where there are presumed similarities in terms of social standing and vulnerabilities. Wolfe (1996) insists that inequality persist because the researcher is able to leave the field, and Owen (2005) recognises her national or native status as significantly more powerful than the positions of the non-native refugee women in her study. While these and other studies in power and ethics in the research field proved helpful as I developed an tools for self-reflexive engagement, few were helpful as a basis to address the issue raised by the ethics committee.

We became aware that as an African pentecostal feminist scholar, who by making assertions that migrant women do not necessarily 'live in vulnerable circumstances and may have/ most likely have been traumatized by rape in dependent relationships' nor that 'telling their story' necessarily involve sexual or physical violence - I was pushing back against an entire discipline of assumptions about my insider position, the agency-versus-vulnerability of migrant women. Finally, I felt the weight of the expectation that I should conform to the disciplinary/ knowledge regimes regarding data collection. In this my knowledge and lived experience was not only irrelevant but an obstacle to good research practice. Having attended to the Ethics Committee's queries, we were surprised to find that, when a further three months later, instead of being satisfied with the changes made the ethics application was again denied (now six months since the first submission). The basis for the reservations were stated as follows:

- Referral Service for Counselling: It is suggested that an independent psychologist / counsellor be present during the data generation process to protect participants from trauma which could be triggered by the incidents that they are required to recall. Participants could find the process of seeking counselling difficult, inconvenient and expensive, i.e. telephone and transport costs, taking leave from work etc. Can this option be considered?

- Location of Interviews: if Faith Based Organisations 'further interfere with and prescribe women's sexual and reproductive health choices' (pg3), then the church might not be a 'safe place' as per the PI's declaration / perception. Please can this be relooked at. 
This response was unexpected but not entirely surprising. It was unsurprising because the committee maintained their line of argument and asserted a paternalistic and protectionist approach to ethical governance (Vadeboncoeur, Townsend, Foster \& Sheehan 2016). What was unexpected was the elevated levels of oversight, such as the committee insisting that 'an independent psychologist / counselor be present during the data generation process to protect participants'. This provoked three critical concerns for us: (1) that the committee assumed that the presence of a therapeutic observer would moderate the interaction; (2) that the researcher lacked the competence to empathise and be sensitive to migrant women's lived experiences; and (3) that the researcher lacked the academic competence to assess affect during interview, terminate meetings and make referrals for further counselling. Further, we found that the reasons provided for including a therapeutic counsellor in the interview process disregarded the referral process that had been put in place, and likewise, they disregarded that fact that sourcing the service of an independent therapist or counsellor would be prohibitively expensive, especially for a migrantresearcher. It was difficult not to regard the recommendations as punitive or infantilizing. Thus following lengthy discussions, my supervisor and I drafted a joint response and sent it the University Ethics Committee:

There is no indication or suggestion in the proposal, or the interview schedule that these women are in any way traumatised by their public health experiences. These are imagined factors inserted by the committee. As a Christian migrant woman myself, I know intimately what these women experience and it is a prejudice to assume that we are all raped and traumatised. The women I intend to interview are just normal women who have migrated to South Africa.

All the women to be interviewed live and work locally (in the city centre) and will not need to travel to the interview. As with any situation of interviews, I will negotiate a suitable time for me to meet with each participant at a time that suits them-for example, during their lunch break.

Finally, after discussing with my supervisor, we both feel that apart from the fact that there is no evidence or suggestion of trauma, the presence of a psychologist / counsellor during the data generation process is problematic: (a) it is likely to be more intimidating for the 
women to have two people present during the interviews; (b) it creates a context where these women are imagined as victims only and in need of rescue or protection, (c) this undermines me as a researcher (a black, migrant women researcher) in that it assumes that I might not manage the issue that will come up during the interview.

It is our view that the referral services and information that has been put in place is sufficient-especially considering the fact that it is just down the road from where most of the women live and work.

The ethics committee failed to engage with our argument and merely submitted the following response two days after we had sent the letter above: 'Please can the Referral Service for Counselling be revised as the response given was not accepted'. This sparked a week of exhaustive deliberation over the required referral conditions, during which time I demonstrated to the Ethics Committee that we could not find an independent therapist or counsellor who would agree to be present in the room during interviews (pro bono), nor could we secure a similar service from either Lifeline counsellors or the Child and Family Centre therapists at the university. The University Ethics Committee finally conceded that I had made every effort, and then agreed that the initial referral service provided would suffice, and ethical clearance was finally granted more than six months after the initial application was submitted.

As young woman researcher of colour, this process left me devastated and frustrated in that not only had my research project been misinterpreted by the ethics committee but I also felt undermined and incompetent. Having clearly argued and presented a rationale for a feminist research project where my own positionality and proximity to the social worlds of the research participants were regarded as an asset, we struggled to see how in its deliberations the ethics committee seemed to re-present my positionality as a migrant women researcher as an obstacle to doing good research. The University Ethics Committee's politicization and infantalization of migrant women impeded on their ability to assess and review the research proposal on its own merit. Drawing from Patricia Hill Collins' 'politics of containment', Mirza goes on to argue that women of colour are 'watched and unraced', that results in "black scholars feeling "out of place" in white institutions of higher learning at great emotional and psychological costs to the bearer of that difference' (Mirza 2015:5). 


\section{Discussion: Empowering Methodologies}

We found that apart from the alienating institutional culture - where women of colour have been imagined either as sexualised, vulnerable subjects deserving of patronage - as elaborated in the work of scholars such as Collins (1998), Mirza (2015) and Ahmed (2012), the traditionally positivist ethics committee emerges as an institutional forum that further frustrates feminist research projects. The many presumptions about the research proposal I submitted shows how post-positivist or postcolonial feminist and race critical data production methods are placed at odds with protectionist ethics review committees. In our experience, the committee presumed that telling their stories about mediating sexual and reproductive choices between faith and family would trigger traumatic experiences for migrant women, and that telling their stories required additional therapeutic safeguards during the interview process. This latter requirement relies on the problematic idea of migrant women as vulnerable and subjects of traumatic histories - potentially reinscribing this idea on the researcher or the research participants.

With increasing critiques of conventional research ethics, especially research on women's lived experience, the social sciences has seen the development of unique feminist methodologies (Kirsch 1999). Most of these debates occurred in the western academy, where feminist researchers sought recognition and space for both a revision of epistemology and methodological practice. During the late 1990s debates in research ethics saw justice and rights discourses, being replaced with or increasingly incorporating feminist ethics of care and solidarity (Ruddick 1996; Edwards \& Mauthner 2012). In our deliberations with the University Ethics Committee we sought to move beyond the justice-vs-solidarity binary, and found that despite the fact that we shared a commitment to reducing the harm to the research participants, our approaches different in our strategies for achieving our goal. While the (positivist) University Ethics Committee emphasised the enforcement of protocols and safeguards, the research proposal was intentionally designed to reduce the power-differential between the researcher and the participants, as well as to empower the migrant women participants as co-producers of knowledge (Jansen \& Rae Davis 1998). From the work of Campbell, Greeson and FehlerCabral (2010), Harding and Norberg (2005), Irwin (2006) we see how feminist methodologies endorse more democratic approaches, emphasizing care, compassion, solidarity, and collaboration between researchers and partici- 
pants. Although we found that the University Ethics Committee's objections brought on a crisis of confidence - they challenged our epistemological stance that migrant women are not necessarily victims - we were able to defend a methodology defined by ethics of solidarity, empowerment and the social justice.

In the end I was able to complete interviews with six African migrant women, in locations of their choosing (two at their places of work and four preferred to do their interviews at the church). The data production phase proved wonderfully rewarding and while it demanded rigorous self-reflexivity, I concluded that the opinions offered by the participants were significantly influenced by our shared positionalities and experiences as migrant women in South Africa, as well as our being religious women mediating our sexual and reproductive choices in the light of their Pentecostal faith. To this end we, as the authors, decided to cite participants' observations that support this conclusion. With respect to accessing social security, and public health services in particular, one participant Zodwa (anonymised) said:

It's not easy. If you don't have ID especially the times they find that you are a foreigner, they treat you different. It's just not easy... it's like they look at you as another human being, you are more like they don't consider you as a human being but you are more like a stranger to them. So it's not easy.

Similarly, when another participant was asked how she mediated her Pentecostal church's teaching about sex and her own sexual and reproductive choices, Kwekhu (anonymised), a 26-year old single woman noted:

About sex before marriage, they teach a lot about sex before marriage but I am a human being, I have some sexual desires so I had to sleep with somebody soon or later. This sex before marriage it doesn't really work for me.

The pentecostal church teaches sexual abstinence and discourages church members, and migrant women in particular, from the opportunity to explore other available forms of family planning. It is clear that Zodwa, like other migrants, her general experience is being treated as 'other' human or strangers by the society - yet all the while asserting their dignity. Similarly, Kwekhu also 
asserts her humanness with respect to not being a machine but a woman with feeling and desires. Ultimately, what is evident from the intimate and frank tone of these responses is the participants' degree of comfort, safety and selfexpression (agency). We agree that these findings were enabled as a result of the researcher's affinity with, proximity to the lived experience of the Zodwa and Khethu. In addition to the rich data collected during the research process, we were also struck by the high degree of safety that participants felt. This is evident from Khethu's confession that she does not adhere to the sexual abstinence taught by her Pentecostal church, and thus her sense of comfort to express illicit views can be understood in terms of the researcher's empathy, vulnerability and solidarity born out of the feminist methodology employed in this study. In the final analysis, the research project progressed as I had imagined and so through privileging women's lived experiences, the reduced powerdifferential between myself and the participants, I was able to, firstly, apply feminist research principles throughout the project and secondly, in this case I was able to privilege the agency and self-representation of migrant women.

\section{Conclusion}

While this research proposal and subsequent study sought to find out whether, or how faith and migrant status influence women's sexual and reproductive health choices, this article focussed on the ideological objections I faced in seeking ethical approval for my study. Despite asserting the focus of the study, as researcher and supervisor, we had to repeatedly justify the feminist rationale of the project insofar as it flattened power relations between the researcher and the participants, and its recognition of migrant women as agentic and selfdetermining persons. As a researcher, I faced a great deal of frustration and humiliation for having to constantly having to prove my ability as a scholar. As supervisor, the second author grew to appreciate the particular ways that women of colour are patronised as being out of place in the university and being fixed as post-traumatic victim of some possible past violence. We both came to appreciate that beyond the alienating institutional culture of higher education, research procedures, protocols and ethics governance structures also serve to regulate women and black people's access to and legitimacy in the academy.

This article is not a critique of our particular university, not an indictment of the University Ethics Committee, but rather an attempt to 
highlight processes through which particular, and often patriarchal, knowledge regimes are enforced by ethics governance bodies, as if they are universally applicable. In our examination of the ethics committee's queries, we noted not only the infantalization of black women researchers as novice researchers, but also the representation of migrant women as perpetual victims, thus sustaining regimes of patronage that regulate black women's access and mobility in the academy. Further, it reinforces ideas about women of colour and migrant women as necessarily belonging to vulnerable research populations. It was our position that, if we conceded the epistemological and feminist methodological orientation of the research proposal due to the demands of the ethics committee, this would have result in loss of migrant women's perspectives regarding sexual and reproductive choices among African Pentecostal migrants. It would also have further delayed methodological innovation that emerges from feminist, race-critical, migrant-centred research. Finally, we came to recognise the particular ways that black women researchers' pedagogies and methodologies of empowerment and solidarity are excessively scrutinized in the name of good science.

Finally, what we have set out to highlight in this article is the need to problematise the ethics of University Ethics Committee insofar as the inherited epistemological traditions are not ideologically neutral. Further, with the changes in methodological practices over recent decades - especially with the development of feminist and indigenous research methodologies, ethics committee protocols have to similarly evolve to review less positivist research proposals. Having established that traditional positivist approaches are not universally applicable and such review processes do not apply adequately to research projects characterised by social justice - whether in pursuit of race, class and gender equity or sexual diversity. It is our contention that ethics committees must similarly apply principles of reflexivity with respect to its own inherited and institutional positionality. Such reflexivity of ethics and power inherent in review processes might not only facilitate the development and recognition of innovative research methods, but also reduce the alienating assumptions about black women researchers, as well as the migrant communities we research.

\section{Funding acknowledgement}

The research project this article draws from, was funded by NRF Thuthuka Programme, and the Church of Sweden's Gender, Religion, and Health Project. 


\section{Bibliography}

Abbott, L. \& C. Grady 2011. A Systematic Review of the Empirical Literature Evaluating IRBs: What we Know and What we Still Need to Learn. Journal of Empirical Research on Human Research Ethics 6,1: 3 - 19. https://doi.org/10.1525/jer.2011.6.1.3

Adogame, A. 2008. 'I am Married to Jesus': The Feminization of New African

Diasporic Religiosity. Archives de sciences sociales des religions $53 e$ Anne, N.143, Christianisme du Sud 'aI' 'epruve de I'Europe 143:129 149.

https://doi.org/10.4000/assr.17133

Agadjanian, V. \& S.T. Yabiku 2014. Religious Affiliation and Fertility in a Sub-Saharan Context: Dynamic and Lifetime Perspectives. Population Research and Policy Review 33, 5:673 - 691.

https://doi.org/10.1007/s11113-013-9317-2

Ahmed, S. 2012. On Being Included: Racism and Diversity in Institutional Life. Durham, NC: Duke University Press.

https://doi.org/10.1215/9780822395324

Anderson, A. 2006. The Proliferation and Varieties of Pentecostalism in the Majority World. In Droogers, A., C. van der Laan \& W. van Laar (eds.): Fruitful in this Land: Pluralism, Dialogue and Healing in Migrant Pentecostalism. Geneva: Boekencentrum Zoetermeer, and WCC Publications.

Asamoah-Gyadu, K.J. 2010, Religious Education and Religious Pluralism in the New Africa. Religious Education 105, 3: 238 - 244.

https://doi.org/10.1080/00344081003771925

Brodwin, P. 2003. Pentecostalism in Translation: Religion and the Production of Community in the Haitian Diaspora. American Ethnologist 30, 1: 85 101.

https://doi.org/10.1525/ae.2003.30.1.85

Burchardt, M. 2011. Challenging Pentecostal Moralism: Erotic Geographies, Religion and Sexual Practices among Township Youth in Cape Town. Culture Health and Sexuality 13, 6: 669 - 683.

https://doi.org/10.1080/13691058.2011.566356

Burgess-Proctor, A. 2015. Methodological and Ethical Issues in Feminist Interviews with Abused Women: Reflections on Participants' Vulnerability and Empowerment. Women's Studies International Forum 48,1: 124 - 134. 
https://doi.org/10.1016/j.wsif.2014.10.014

Campbell, J.C., RM. Greeson \& G. Fehler-Cabral 2014. Developing Recruitment Methods for Vulnerable, Traumatized Adolescents: A

Feminist Evaluation Approach. American Journal of Evaluation 35,1: 73

- 86.

https://doi.org/10.1177/1098214013506251

Caplan, P. 2003. Anthropology and Ethics. In Caplan, D. (eds.): The Ethics of Anthropology: Debates and Dilemmas. London and New York:

Routledge.

https://www.amazon.com/Ethics-Anthropology-Debates-

Dilemmas/dp/0415296420

Caulfield, T., N. Ries \& G. Barr. 2011. Variation in Ethics Review of Multisite Research Initiatives. Amsterdam Law Forum 3: 85.

Collins, P. 1991. Learning from the Outside Within: The Sociological Significance of Black Feminist Thought. In Fonow, M.M. \& J.A. Cook (eds.): Beyond Methodology. Bloomington: Indiana University Press.

Dingwall, R. 2008. The Ethical Case against Ethical Regulation in Humanities and Social Science Research. Twenty-First Century Society 3,1: 1 - 12. https://doi.org/10.1080/17450140701749189

Edwards, R. \& M. Mauthner 2012. Ethics and Feminist Research: Theory and Practice. In Miller, T., M. Birch, M. Mauthner \& J. Jessop (eds.): Ethics in Qualitative Research. London: SAGE.

Foley, E.E. 2005. HIV/AIDS and African Immigrant Women in Philadelphia:

Structural and Cultural Barriers to Care: AIDS Care. Psychological and Socio-medical Aspects of AIDS/ HIV 17,8: 1030 - 1443.

https://doi.org/10.1080/09540120500100890

Garrard, E. \& A. Dawson 2005. What is the Role of the Research Ethics

Committee? Paternalism, Inducements, and Harm in Research Ethics. Journal of Medical Ethics 31: 419 - 423.

https://doi.org/10.1136/jme.2004.010447

Gebara, I. 1991. Longing for Running Water: Ecofeminism and Liberation. New York: Fortress Press.

https://www.amazon.com/Longing-Running-Water-Ecofeminism-

Reflections/dp/0800631838

Goodyear-Smith F., B. Lobb, G. Davies, I. Nachson \& S.M. Seelau 2002. International Variation in Ethics Committee Requirements: Comparisons across Five Westernised Nations. BMC Med Ethics 3,2: 1 - 8. 
https://doi.org/10.1186/1472-6939-3-2

Hammersley, M. 2009. Against the Ethicists: On the Evils of Ethical Regulation. International Journal of Social Research Methodology 12,3: $211-225$.

https://doi.org/10.1080/13645570802170288

Harding, S. \& K. Norberg. 2005. New Feminist Approaches to Social Science Methodologies: An Introduction. Signs 30,4: 2009 - 2015.

https://doi.org/10.1086/428420

Hondagneu-Sotelo, P. 1999. Gender and Contemporary U.S Immigration. American Behavioral Scientist 42: 565 - 576.

https://doi.org/10.1177/00027649921954363

Irwin, K. 2006. Into the Dark Heart of Ethnography: The Lived Ethics and Inequality of Intimate Field Relationships. Qualitative Sociology 29,2: $155-175$.

https://doi.org/10.1007/s11133-006-9011-3

Jacobs-Huey, L. 2002. The Natives are Gazing and Talking Back: Reviewing the Problematics of Positionality, Voice and Accountability among 'Native' Anthropologists. American Anthropologist 104, 30: 791 - 804.

https://doi.org/10.1525/aa.2002.104.3.791

Jansen, G. \& D. Rae Davis 1998. Honoring Voice and Visibility: SensitiveTopic Research and Feminist Interpretive Inquiry. Affilia 13,3: 289 - 311. https://doi.org/10.1177/088610999801300303

Keskinen, S., S. Tuori, S. Irni \& D. Mulinari (eds.). 2012. Complying with Colonialism: Gender, Race and Ethnicity in the Nordic Region. Farnham: Ashgate Publishing Ltd.

Kirsch, G. 1999. Ethical Dilemmas in Feminist Research: The Politics of Location, Interpretation, and Publication. Albany: State University of New York Press.

Levine, R. 1988. Ethics and Regulation of Clinical Research. New Haven: Yale University Press.

https://www.amazon.com/Ethics-Regulation-Clinical-ResearchSecond/dp/0300042884

McCutcheon, R. 2003. Manufacturing Religion. The Discourse on Sui Generis Religion and the Politics of Nostalgia. Oxford: Oxford University Press. https://www.amazon.com/Manufacturing-Religion-Discourse-PoliticsNostalgia/dp/0195166639

Mernissi, F. 1991. Women and Islam: An Historical and Theological Enquiry. 
London: Blackwell Publishers.

https://www.amazon.com/Women-Islam-Historical-TheologicalEnquiry/dp/0631169059

Mirza, H.S. 2015. Decolonizing Higher Education: Black Feminism and the Intersectionality of Race and Gender. Journal of Feminist Scholarship 7/8:1 - 12 .

Nunez, L. 2014. Faith Healing, Migration and Gendered Conversions in Pentecostal Churches in Johannesburg. In Healing and Change in the City of Gold. Johannesburg: South Africa.

Owen, J. 2005. Fieldwork in Shared Spaces: Positionality Power and Ethics of Citizen Anthropologists in Southern Africa: Shifting Power Dynamics in Muizenberg. Anthropology Southern Africa 28,3\&4: 124 - 126.

Peberdy, S. \& N. Dinat 2005. Migration and Domestic Workers: Worlds of Work, Health and Mobility in Johannesburg. (Migration Policy Series No. 40.) Cape Town: South African Migration Project.

http://samponline.org/wp-content/uploads/2016/10/Acrobat40.pdf

Ruddick, S. 1996. Maternal Thinking: Towards a Politics of Peace. Boston, MA: Beacon Press.

https://www.amazon.com/Maternal-Thinking-Toward-Politics-

Peace/dp/0807014095

Scheppers, E., E. van Dongen, J. Dekker, J. Geertzen \& J. Dekker 2006.

Potential Barriers to the Use of Health Services among Ethnic Minorities:

A Review. Family Practice 23,3: 325 - 348.

https://doi.org/10.1093/fampra/cmi113

Simone, A. 2000. Going South: African Immigrants in Johannesburg. In Nuttal, S. \& C.A. Michael (eds.): Senses of Culture: South African Cultural Studies. Cape Town: Oxford University Press.

Smith, L.T. 2006. Indigenous Methodologies: Research and Indigenous Peoples. London: Zed Books.

Vadeboncoeur, C., N. Townsend, C. Foster \& M. Sheehan. 2016. Variation in University Research Ethics Review: Reflections Following an Interuniversity Study in England. Research Ethics 12,4: 217 - 233.

https://doi.org/10.1177/1747016116652650

Wolf, D.L. 1996. Feminist Dilemmas in Fieldwork. Boulder: Westview Press. Yeatman, S. \& J. Trinitapoli 2008. Beyond Denomination: The Relationship between Religion and Family Planning in Rural Malawi. Demographic Research 19, 55: 1851 - 1882. 
https://doi.org/10.4054/DemRes.2008.19.55

Yebei, V.N. 2000. Unmet Needs Beliefs and Treatment-seeking for Infertility among Migrant Ghanaian Women in the Netherlands. Reproductive Health Matters 8, 16: 134 - 141. https://doi.org/10.1016/S0968-8080(00)90195-2

Delipher Manda Religion, Gender and Health School of Religion, Philosophy and Classics University of KwaZulu-Natal delipher.manda@gmail.com

Federico Settler Sociology of African Religions School of Religion, Philosophy and Classics University of KwaZulu-Natal settler@ukzn.ac.za 